\title{
Polysaccharide Fibers as Matrices for Solid-Surface Fluorescence
}

\author{
Svetlana M. Rogacheva, ${ }^{1}$ Anna B. Shipovskaya, ${ }^{1,2}$ Anna V. Strashko, ${ }^{1}$ \\ Tamara I. Gubina, ${ }^{1}$ Elena V. Volkova, ${ }^{1}$ and Andrey G. Melnikov ${ }^{1}$ \\ ${ }^{1}$ Gagarin Saratov State Technical University, Politekhnicheskaya Street 77, Saratov 410054, Russia \\ ${ }^{2}$ Chernyshevsky Saratov State University, Astrakhanskaya Street 83, Saratov 410012, Russia \\ Correspondence should be addressed to Svetlana M. Rogacheva; smro13@yandex.ru
}

Received 1 September 2014; Accepted 20 November 2014; Published 8 December 2014

Academic Editor: Vitor Sencadas

Copyright ( 2014 Svetlana M. Rogacheva et al. This is an open access article distributed under the Creative Commons Attribution License, which permits unrestricted use, distribution, and reproduction in any medium, provided the original work is properly cited.

Fibers of cellulose diacetate (CDA) and chitosan (CTS) of polycationic and polybasic forms were tested as matrices for solid-surface fluorescence (SSF) of several fluorescent probes-eosin Y, trypaflavine, and pyrene. The morphology and surface potential of these matrices were examined. The influence of structural and energetic characteristics of the fibrous polysaccharide materials at SSF of the probes was shown. Fluorescence was studied in aqueous solutions of eosin Y and trypaflavine, in water-ethanolic and watermicellar surfactant media of pyrene, before and after dynamic sorption of the dyes on fibers and in the adsorbed state. The surface of CDA fiber was shown to be capable of sorbing trypaflavine from water and pyrene from water-micellar surfactant media of various types, so it can be a promising matrix for SSF of pyrene and trypaflavine and their chemical analogs. The Coulomb interactions were proposed to determine eosin Y and trypaflavine concentration on the surface of CTS matrices and the SSF of these probes. The CTS fibers were permeable to hydrophobic pyrene dissolved in an ethanol-water medium or solubilized in the micelles of ionic surfactants.

\section{Introduction}

Analytical methods usually include sample separation and preconcentration, which have a direct impact on their accuracy, precision, and detection limits. At present, considerable attention is paid to solid-phase extraction (SPE), which involves adsorption of analytes on solid sorbents. SPE is widely applied in the analysis of various chemical compounds from environmental samples, body fluids, food, and so forth [1-5].

SPE can be the first stage of the spectrofluorimetric determination of an analyte in a solid phase. Nowadays, solidsurface [6] or solid-matrix [7] luminescence is successfully applied for trace quantification of organic and inorganic compounds in various media. Data are available on the solid-surface fluorescent (SSF) analysis of polycyclic aromatic hydrocarbons $(\mathrm{PAH})$ in aqueous media $[3,8]$, anticonvulsant carbamazepine and its main metabolite in human serum [9], retinol in aqueous micellar media with a low quantity of a short-chain alcohol [10], caffeine in urine, plasma and serum [11], doxycycline in water media [12], explosives in a vapor phase [13], $\mathrm{Al}(\mathrm{III}), \mathrm{Be}(\mathrm{II})$, and $\mathrm{Ga}(\mathrm{III})$ in water [14], and so forth. Since SSF combines sorption preconcentration with the direct measurement of the analyte fluorescence, it can be used in chemical sensors [15] or even nanosensors [16] for intracellular analysis.

There are many solid materials with various properties which are suitable for SSF applications. Among them are silica gel [12, 17], zeolite [18], foamed polyurethane [19], cellulose [14], and so forth. Decyl methacrylate was used as a matrix for fluorescent nanosensors [16]. The unique electrical, mechanical, and chemical properties of nanomaterials have sparked great interest in their usage for SSF as well [11, 20, 21].

The availability and low cost of the raw materials which a matrix is made of are important for its selection. Therefore, the interest in materials based on natural polysaccharides and their derivatives is growing. The cellulose matrix, being a solid particulate material of a microfiber structure, is most popular as a sorbent for SSF [14, 22, 23]. Cellulose's disadvantages, however, are its disposability and the relatively low efficiency of sorption due to the hydrophilic nature of the material. Therefore, searching for other promising 
polysaccharide materials to design matrices for analyte sorption is important.

Polymeric materials based on cellulose diacetate (CDA) have a number of valuable properties. They are widely used as sorbents in various industries and as membranes for the purification and preconcentration of proteins, enzymes, and antibiotics [24, 25]. The aminopolysaccharide chitosan (CTS) is promising as well. Materials on its basis exhibit a high sorption capacity $[26,27]$ and serve effective sorbents of some nonpolar compounds (dyes, surfactants), heavy metal ions, and so forth $[28,29]$. Depending on the technique of formation, CDA and CTS materials can be prepared in various morphological forms such as films or fibers [25, 27]. This allows one to vary the surface characteristics of the polymeric sorbent. The presence of such a complex of useful properties determines good prospects of CDA and CTS for the design of new materials for purification, concentration, and analysis purposes.

The aim of this study was to assess the ability of polysaccharide matrices based on CDA and CTS fibers to interact with substances of different types for their application in solid-surface fluorescent analysis.

\section{Experimental Methods}

2.1. Polysaccharide Matrices. Fibrous materials made of CDA and CTS were used in the study. Polymer characteristics are as follows: CDA with a viscosity-average molecular weight $\overline{\mathbf{M}}_{\eta}$ of $77 \mathrm{kDa}$, an acetylation degree of $55 \%$, and a $3 \%$ moisture, used for the production of acetate filaments of textile purposes (Technofilter Ltd., Vladimir, Russia); CTS with $\overline{\mathrm{M}}_{\eta}=200 \mathrm{kDa}$, a deacetylation degree of $82 \mathrm{~mol} . \%$, and a 9\% moisture (JSC "Bioprogress," Shchelkovo, Russia). CDA and CTS fibers were prepared from polymer solutions in $70 \%$ acetic acid (reagent grade) by electrospinning at the Educational \& Research Institute of Nanostructures and Biosystems (Chernyshevsky Saratov State University, Russia). CTS in these fibers existed in two chemical forms, namely, polycationic or polybasic. To convert CTS from polycationic to polybasic form, the samples were incubated in $1 \mathrm{~N} \mathrm{NaOH}$ solution for an hour. Then they were washed with distilled water until $\mathrm{pH} 7$ and dried at $20^{\circ} \mathrm{C}$ during one day.

2.2. Materials. Eosin Y, trypaflavine (Sigma, USA), and pyrene (Fluka, Germany) of the Purum brand were used as fluorescent probes. The main component content in all probes was $96 \%$. $2.96 \times 10^{-6} \mathrm{M}$ aqueous solutions of eosin $\mathrm{Y}(\mathrm{pH}=$ 5.3), $1.21 \times 10^{-6} \mathrm{M}$ aqueous solution of trypaflavine $(\mathrm{pH}=7.4)$, and water-ethanolic $(\mathrm{pH}=6.9)$ and water-micellar surfactant solutions of pyrene with a concentration of $2.24 \times 10^{-5} \mathrm{M}$ were used in our experiments.

A stock solution of pyrene was prepared by dissolving an accurate weight in ethanol. The resulting solution was stored in a dark place to prevent photochemical destruction. Waterethanolic pyrene solutions for tests were prepared by diluting the stock solution with distilled water immediately prior to use.
Aqueous micellar solutions of pyrene were prepared using such surfactants as sodium dodecyl sulfate, SDS (LenReaktiv, St. Petersburg, Russia), cetyltrimethylammonium bromide, CTAB (Sigma, Alfa Aesar Manufacturer, Great Britain), and polyoxyethylene (10) mono-4-isooctylphenyl ether, TX-100 (ACROS ORGANICS, USA). The pure substance content was 98-99\% for all surfactants. The weight of pyrene was dissolved in $0.5 \mathrm{M}$ solution of the surfactant, diluted with distilled water to the final surfactant concentration of $10^{-2} \mathrm{M}$. The $\mathrm{pH}$ of the aqueous micellar solutions of pyrene was $8.8,8.1$, and 8.5 for SDS, CTAB, and TX-100, respectively. The $\mathrm{pH}$ of the solutions was measured with a $\mathrm{pH}$ meter $\mathrm{pH}-673 \mathrm{M}$ ("Measurement Equipment" Ltd., Moscow).

2.3. Testing Methods for CDA and CTS Fibers. Surface morphology was evaluated by scanning electron micrographics (SEM) on MIRA \ILMU electron scanning microscope (Tescan, Czech Republic) at a voltage of $8 \mathrm{kV}$ and a conductive current of $60 \mathrm{pA}$. A gold layer of $5 \mathrm{~nm}$ thickness was sprayed onto the samples with a K450X carbon coater device (Germany); the spraying current was $20 \mathrm{~mA}$, with the spraying duration of $1 \mathrm{~min}$.

The surface potential $(\xi, \mathrm{mV})$ of fibrous matrices was measured with a surface potential sensor (Nima KSV, Finland).

2.4. Conditions of the Solid-Phase Sorption of Probes. The sorption of fluorescent probes was performed in the dynamic mode. To this purpose, the solutions $(V=10 \mathrm{~mL})$ were passed through the fiber five times, using a disposable sterile syringe Master UNI "PharmLine Limited" (Cornwall Buildings, Birmingham, Great Britain) with a sorbent holder and a receiving reservoir. The mass of the sorbents was $0.05 \pm 0.01 \mathrm{~g}$. The fibrous matrices were then dried at room temperature until constant weight was reached.

2.5. Fluorescent Analysis. The fluorescence spectra of fluorescent probes in solution and in an adsorbed state on solid matrices were recorded on a LS 55 fluorescent spectrometer from Perkin-Elmer (Perkin-Elmer Life and Analytical Sciences, Inc., USA). A xenon lamp operating in pulse mode with a frequency of $50 \mathrm{~Hz}$ served as a source of radiation. The Monk-Gillieson monochromators were employed. The fluorescence of solutions was measured in a standard quartz cuvette with $l=1 \mathrm{~cm}$, whilst a holder for solid samples was used for solid matrices.

The fluorescence of trypaflavine, eosin Y, and pyrene was measured within the spectral range of $475-575,520-$ 580 , and $350-450 \mathrm{~nm}$, respectively; the wavelength setting accuracy was $1 \mathrm{~nm}$. The excitation radiation wavelength for trypaflavine, eosin $\mathrm{Y}$, and pyrene was 460,500 , and $320 \mathrm{~nm}$, respectively. The scanning rate was $200 \mathrm{~nm} / \mathrm{min}$.

The extraction degree $(R, \%)$ of the probes was determined as [23]

$$
R=\frac{I_{\max }^{\prime}-I_{\max }^{\prime \prime}}{I_{\max }^{\prime}} \cdot 100 \%,
$$

where $I_{\max }^{\prime}$ and $I_{\max }^{\prime \prime}$ are the maximum values of fluorescence intensity $\left(I_{\mathrm{Fl}}\right)$ of the substance in the source solution and in 


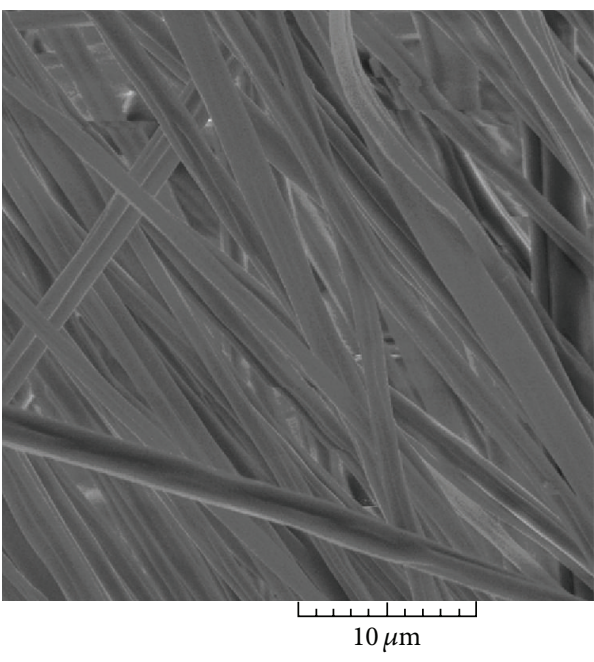

(a)

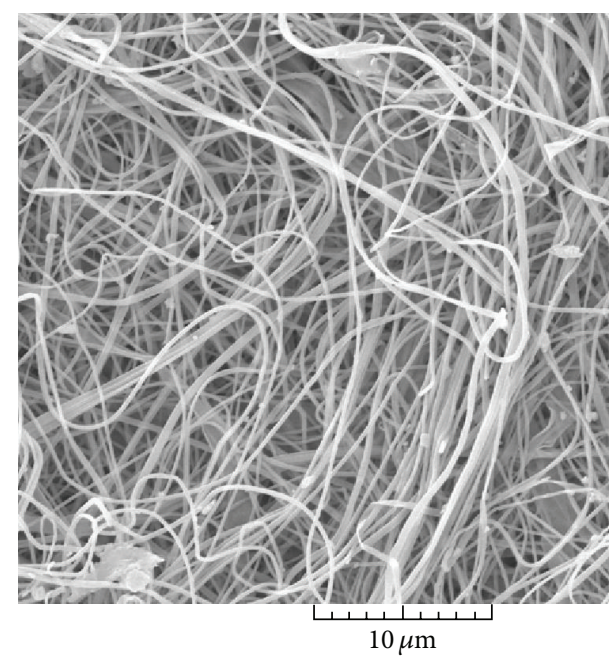

(b)

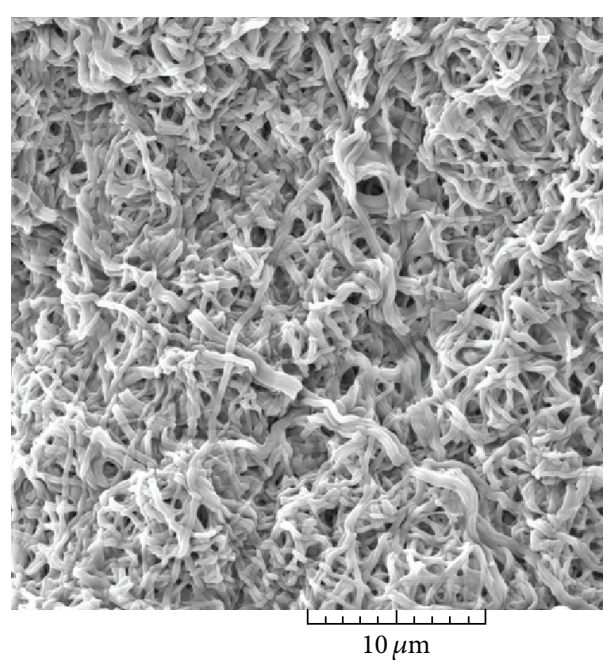

(c)

FIgURE 1: The SEM of the morphological surface structure of CDA (a) and CTS in the polycationic (b) and the polybasic (c) form.

that after sorption concentration on the fiber. $I_{5}$, that is, the value of $I_{\mathrm{Fl}}$ of the fifth vibronic band in the spectrum, was used for pyrene.

The relative fluorescence intensity $\left(I_{\mathrm{Fl} \mathrm{Rel}}\right)$ of pyrene in solution was determined as $I_{5} / 1000$, where $I_{5}$ is the maximum value of $I_{\mathrm{Fl}}$ of the fifth vibronic band in the spectrum.

\section{Results and Discussion}

3.1. Material Morphology and Surface Potential. Fibrous materials on the basis of polysaccharides of vegetable and animal origin were used in our studies. CDA is the product of cellulose acetylation, with $50-60 \%$ of the hydroxyl groups replaced by acetate groups. It is insoluble in water, hydrophobic, and highly soluble in process solvents (acetone, methylene chloride), which allows obtaining fibers, films, and membranes on an industrial scale $[24,25]$.
The macromolecule of CTS has a heterochain structure and is built from $D$-glucosamine units (mainly) and $N$ acetyl- $D$-glucosamine units linked by $\beta$-1,4-glycoside bonds. The presence of an amino group in the elementary unit leads to two possible chemical forms of CTS in ready fibers, namely, the polycationic and polybasic forms, depending on the preparation technique used [27]. Polycationic CTS is well soluble in water, whereas the polybasic form is hydrophobic. Fibers made of these two forms of CTS differ in other physicochemical characteristics as well.

We examined the morphology and surface-energy characteristics of several fibrous materials based on CDA and CTS; Figure 1 shows their SEM images.

The material made of CDA is seen to have the highly ordered stacking of fibers whose diameter varies within the range $d=300-3000 \mathrm{~nm}$ (Figure $1(\mathrm{a})$ ). The material made of the polycationic CTS is characterized by the weakly ordered stacking of fibers with $d=150-400 \mathrm{~nm}$ (Figure 1(b)). The material made of the polybasic CTS has a cellular structure 
TABLE 1: Surface potential of the solid fibrous matrices.

\begin{tabular}{lcc}
\hline Polysaccharide & Chemical form & $\xi(\mathrm{mV})$ \\
\hline \multirow{2}{*}{ CTS } & Polybasic & $-192.5 \pm 0.5$ \\
& Polycationic & $+116.5 \pm 1.5$ \\
\hline CDA & - & $+419.0 \pm 1.0$ \\
\hline
\end{tabular}

(Figure 1(c)). When the chemical form of CTS switches from polycationic to polybasic form, the fibers are curved, their diameter increases, and the pore sizes in the material reduce.

The surface potential $\xi$ of our fibrous materials at the interface with air was estimated (Table 1). Bound water in the surface layer of the material was taken into account. The measurement results indicate that the surface of the polycationic and polybasic CTS fibers has a positive and a negative charge, respectively. The absolute value of $\xi$ of the fibrous material of both chemical forms of CTS varies slightly. The CDA fiber surface is characterized by a positive value of the potential, whose modulus by 2.2-3.6 times exceeds this value for the CTS fibers.

Thus, the fibrous polysaccharide materials have different structural and energetic characteristics, which can affect their interaction with organic substrates during SSF analysis.

3.2. Fluorescence of Hydrophilic Dyes in Water and Solid Phases. Two hydrophilic fluorescent dyes of different families, namely, trypaflavine (acriflavine chloride) and eosin Y, were used in our experiments [30].

Trypaflavine is an acridine dye, readily soluble in water. The application areas of trypaflavine are as follows: an antiseptic and an intercalating dye for DNA and proteins investigation [31]. On the basis of probes of a structure similar to methylacridinium-9-carboxamide $\mathrm{N}$-methylacridinium9-methyl carboxylate, fluorescent molecular sensors for halide ions (except $\mathrm{F}^{-}$) based on collisional quenching of a dye have been designed [30].

Eosin $\mathrm{Y}$ is a dye of the xanthene family, soluble in water, very sensitive to $\mathrm{pH}$, and used as a $\mathrm{pH}$ fluorescent probe. It is known as a fluorophore undergoing neither photoinduced proton transfer nor photoinduced electron transfer. When $\mathrm{pH}$ increases, the absorption and emission bands of its acidic form decrease with a concomitant increase in the absorption and emission bands of the basic form [30].

Eosin Y fluorescence and trypaflavine fluorescence were studied in aqueous solutions before and after their dynamic sorption on fibers and in an adsorbed state. As an example, presented are the fluorescence spectra of trypaflavine (Figure 2) and eosin Y (Figure 3) in aqueous solutions before and after sorption on the CDA and CTS fibers, respectively, and in the adsorbed state. We note that eosin $\mathrm{Y}$ is hardly sorbed on CDA, while trypaflavine is poorly sorbed on the CTS fiber.

The spectra of trypaflavine and eosin Y have one fluorescence maximum $\left(I_{\max }\right)$ at wavelengths of 505 and $537 \mathrm{~nm}$, respectively, in both aqueous phase and sorbent phase. The polycationic CTS fiber is an exception, which is found to shift the eosin Y $I_{\max }$ to $\lambda=543 \mathrm{~nm}$. This allows one to evaluate

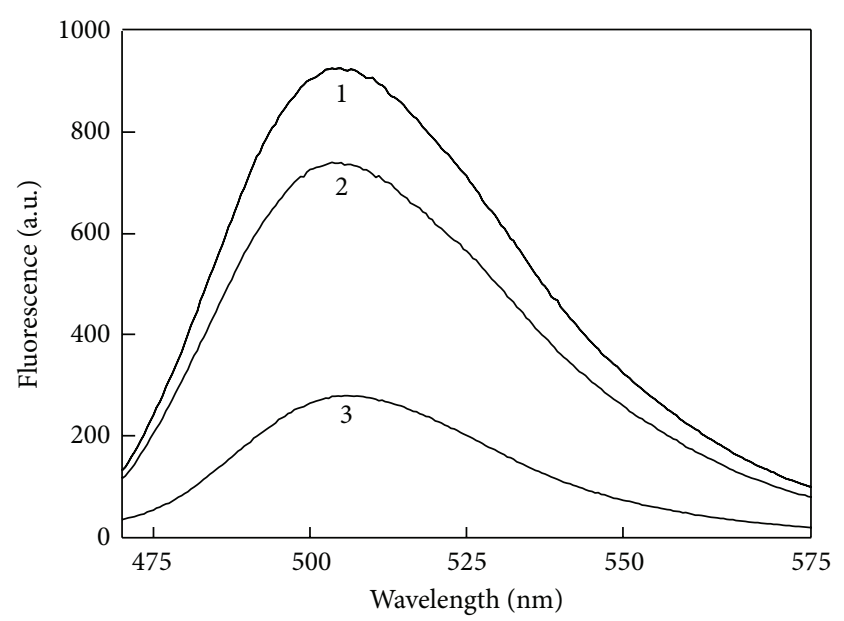

FigURE 2: Fluorescence spectra of trypaflavine $\left(\lambda_{\text {exc }}=460 \mathrm{~nm}\right)$ in aqueous solutions: (1) prior to sorption, (2) after sorption on the CDA fibers, and (3) on the CDA fibers.

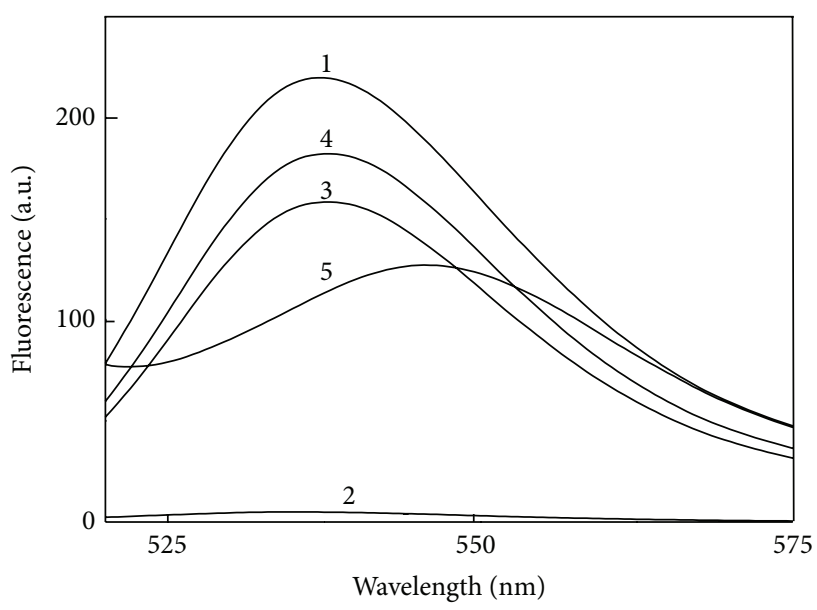

FIgURE 3: Fluorescence spectra of eosin Y $\left(\lambda_{\text {exc }}=500 \mathrm{~nm}\right)$ in aqueous solutions: (1) prior to sorption; after sorption on the CTS fiber, (2) polybasic and (3) polycationic forms; and on the CTS fiber, (4) polybasic and (5) polycationic forms.

the content of substances in solution and on the surface of the sorbent from the value of the fluorescence intensity at the maximum of the spectrum and to estimate the extraction degree $(R, \%)$ of substances.

To compare the signal intensity of a substance in the sorbent phase with its extraction degree, the ratio $I^{\prime} / I_{\max }^{\prime} \cdot 100 \%$ was calculated, where $I_{\max }^{\prime}$ is the $I_{\max }$ of the substance in solution before sorption and $I^{\prime}$ is the $I_{\max }$ of the substance in the adsorbed state on the fibrous matrix. This ratio represents the change in the signal intensity of the substance in its adsorbed state.

Table 2 shows that the extraction degree of trypaflavine and eosin $\mathrm{Y}$ on the CDA fiber is 24.2 and 3.3\%, respectively. Consequently, the CDA fiber interacts better with trypaflavine than with eosin Y. On the contrary, the CTS fibers showed higher affinity for eosin Y than for trypaflavine: 
TABLE 2: The indicators of sorption and fluorescence of the probes on the solid fibrous matrices.

\begin{tabular}{lcccc}
\hline \multirow{2}{*}{ Polysaccharide } & \multicolumn{2}{c}{$R, \%$} & \multicolumn{2}{c}{$I^{\prime} / I_{\max }^{\prime} \cdot 100 \%$} \\
& Trypaflavine & Eosin Y & Trypaflavine & Eosin Y \\
\hline CDA & 24.2 & 3.3 & 30.5 & 4.4 \\
$\begin{array}{l}\text { CTS polybasic } \\
\text { form }\end{array}$ & 18.2 & 95.5 & 40.9 & 81.8 \\
$\begin{array}{l}\text { CTS } \\
\text { polycationic } \\
\text { form }\end{array}$ & 15.9 & 31.8 & 13.6 & 54.5 \\
\hline
\end{tabular}

the extraction degree of eosin $\mathrm{Y}$ on the polybasic and polycationic CTS fibers was 95.5 and $31.8 \%$, respectively.

Trypaflavine concentration on the fiber surface is supported by the appearance of its fluorescence signal on the matrix. The SSF intensity somewhat exceeds the value by which $I_{\mathrm{Fl}}$ has decreased due to sorption. Note that the CDA fiber surface is hydrophobic and has a total positive charge $+419.0 \pm 1.0 \mathrm{mV}$ while acriflavinium chloride in a neutral medium $(\mathrm{pH}=7.4)$ exists in a dissociated state. Chloride ions possibly recharge the fiber surface, and trypaflavine cations partially remain on the surface of the matrix by electrostatic attractions.

At similar extraction degrees of trypaflavine by the CTS fibers of both forms, the intensity of its signal in the adsorbed state on the polybasic CTS fiber was 3 times higher than on the polycationic CTS fiber. The polycationic CTS fiber is hydrophilic with a total surface charge of $+116.5 \pm 1.5 \mathrm{mV}$. Possibly, therefore trypaflavine well penetrates through the pores of the sorbent and sorbs in the bulk of the fibrous matrix rather than on its surface. The surface of the hydrophobic polybasic CTS fibers has a total negative charge, so trypaflavine cations concentrate in the water layer at the surface of the matrix, which results in an increased SSF signal.

A similar effect is observed for eosin Y sorption on the polycationic CTS fiber. When $\mathrm{pH}>5$, eosin $\mathrm{Y}$ is a negatively charged dianion, which favors its concentration at the surface of the matrix with a total positive charge. Its SSF signal amplifies. The polybasic CTS fiber absorbs $95.5 \%$ of eosin Y, that is, three times more than the polycationic CTS fiber. But the SSF signal is increased by 1.5 times only, which, in our opinion, means distribution of the probe inside the bulk of the sorbent, promoted by the cellular structure of this material.

The porous structure of chitosan fibers can be useful for the design of hydrophilic fluorescent probe matrices on their basis for usage in chemical sensors. Porous silica films doped with small molecule fluorophoric metalloporphyrins are examples of high-sensitivity sensors of explosives [13].

3.3. Fluorescence of Pyrene in Water-Ethanolic and WaterMicellar Solutions and on Solid Phases. Pyrene is known as a hydrophobic dye used to explore the polarity of a medium $[30,32]$. It is commonly used as a model compound in studies on PAH [23]. The fluorescence emission spectrum of pyrene is known to have a vibronic structure with five bands within the wavelength range $360-450 \mathrm{~nm}$. The concentration and extraction degree of pyrene are usually determined by the

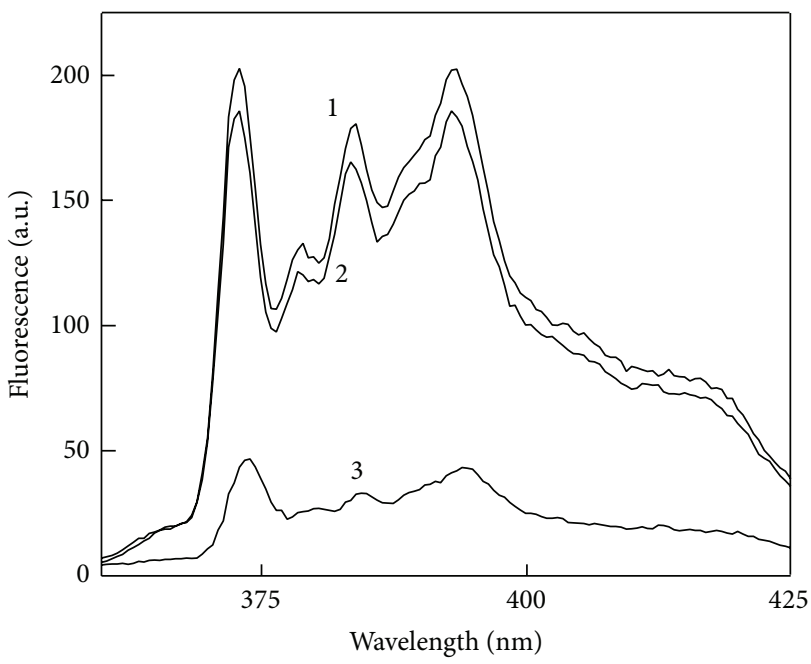

FIGURE 4: Fluorescence spectra of pyrene $\left(\lambda_{\mathrm{exc}}=320 \mathrm{~nm}\right)$ in a waterethanolic solution: (1) prior to sorption, (2) after sorption on the CDA fiber, and (3) on the CDA fiber.

fluorescence intensity $\left(I_{5}\right)$ of the fifth band $(\lambda=395 \mathrm{~nm})$. The intensity ratio $\left(I_{1} / I_{3}\right)$ of the first $(\lambda=375 \mathrm{~nm})$ and third $(\lambda=$ $385 \mathrm{~nm}$ ) bands, called the polarity index, is used to evaluate the polarity of the microenvironment of the probe [32].

We examined the fluorescence of the hydrophobic pyrene probe in water-ethanolic and aqueous micellar solutions before and after dynamic sorption on the fibers and in the solid phase of the sorbents under study.

The pyrene signal intensity in water-ethanolic solutions after sorption on the CDA and CTS fibers decreases slightly. Figure 4 shows the fluorescence spectra of pyrene in waterethanolic solutions before and after sorption on the CDA fibers, which have a typical vibronic structure $[23,32]$. The pyrene signal in the ethanolic solution on the CDA matrix is weak but much higher than expected, given that $R$ is $10 \%$ (Figure 4). The pyrene signal on both types of CTS fibers is almost zero. Consequently, the sorption of pyrene from its ethanolic solution on the fibers proceeds weakly. But after sorption on the CDA fibers the pyrene signal intensity increased, which was also observed with cellulose used as a matrix [23].

To improve the sorption characteristics of the matrix, surfactants of different nature were used: the anionic SDS, the cationic CTAB, and the nonionic TX-100. A similar approach is described in earlier papers $[23,33]$. The actual surfactant concentration $\left(10^{-2} \mathrm{M}\right)$ was above the critical micelle concentration (CMC). The fluorescence spectra of pyrene in aqueous micellar media before sorption, after sorption, and in an adsorbed state on the fibers tested are shown in Figures 5 and 6.

When the spectra of pyrene in the aqueous micellar medium are recorded before sorption (Figures 5 and 6 ), one can conclude that the maximum intensity of fluorescence is observed in the presence of CTAB, while the lowest one is in the case of SDS at the same concentration of pyrene in the medium. This gives evidence of the highest concentration of pyrene in the micelles of the cationic surfactant. 


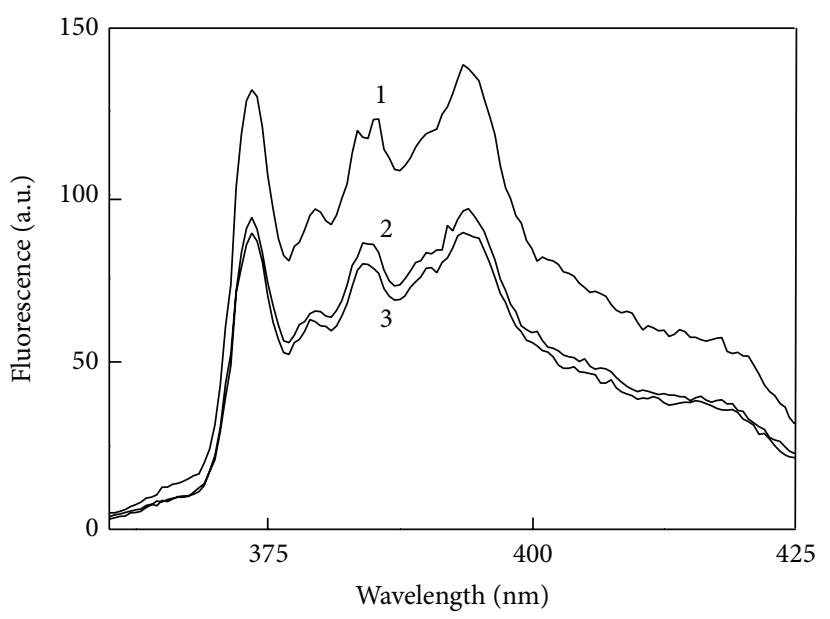

(a)

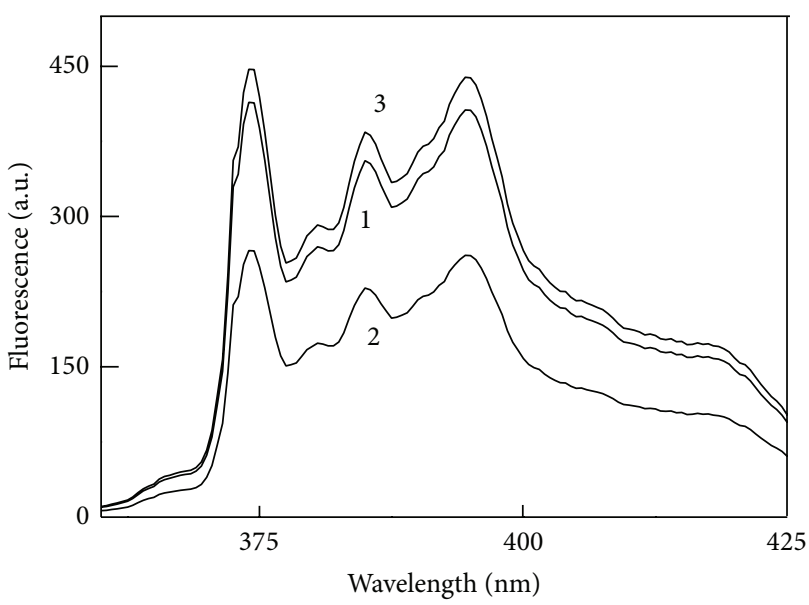

(b)

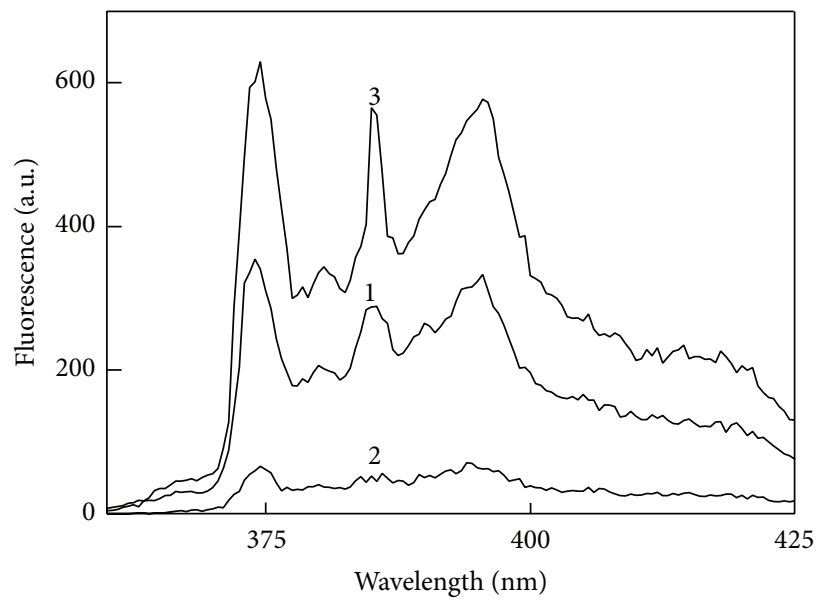

(c)

FiguRE 5: Fluorescence spectra of pyrene $\left(\lambda_{\text {exc }}=320 \mathrm{~nm}\right.$ ) in aqueous micellar solutions of (a) SDS, (b) CTAB, and (c) TX-100: (1) before sorption, (2) after sorption of the CDA fiber, and (3) on the CDA fiber.

TABLE 3: Pyrene extraction degree at its sorption from aqueous micellar solutions on CDA and CTS fibers.

\begin{tabular}{lccc}
\hline Polysaccharide & \multicolumn{3}{c}{$R, \%$} \\
& SDS & CTAB & TX-100 \\
\hline CDA & 38.5 & 32.5 & 82.9 \\
CTS polybasic form & 15.4 & 2.2 & 74.2 \\
CTS polycationic form & 12.8 & 11.5 & 72.1 \\
\hline
\end{tabular}

From the changes in the signal intensity after sorption and the values of the extraction degree of pyrene given in Table 3 it is evident that the CDA fibers have a greater sorption capacity than the CTS ones. Pyrene sorption on the CDA fibers proceeds better from the aqueous micellar media with TX-100 (the extraction degree was $82.9 \%$ ). When the CTS fiber was used, the maximum extraction degrees of pyrene (74.2\%, 72.1\%) were observed for the TX-100 solution as well.

Moreover, it is clear from Figures 5 and 6 that the pyrene signal is greatly enhanced in the adsorbed state on CDA. It is much higher than the signal in solution, which is probably due to concentration of pyrene molecules at the surface of the CDA fibers in a micellar layer [21, 23]. The solutions with SDS are exceptions. At the same time, the values of the fluorescence intensity of pyrene sorbed on the CTS fibers of both forms are close to zero, in spite of the high extraction degree of the probe in the medium with TX-100, which may be due to probe penetration into the pores of the fibrous material and fluorescence quenching.

3.4. Effect of the Surfactant Nature on the SSF of Pyrene. To compare the effect of the surfactants selected on the fluorescence of pyrene in the CDA phase, we calculated the values of the pyrene fluorescence intensity $\left(I_{5}\right)$ in relative terms $\left(I_{\text {rel }}=I_{5} / 1000\right)$. Figure 7 shows that the maximum SSF signal was observed after sorption from the aqueous micellar solution of TX-100 while the minimum signal was from the aqueous micellar solution of SDS. It is noted that the use of the cationic CTAB leads to the maximum enhancement of the pyrene SSF signal at the minimum extraction degree for CDA in this experiment. 


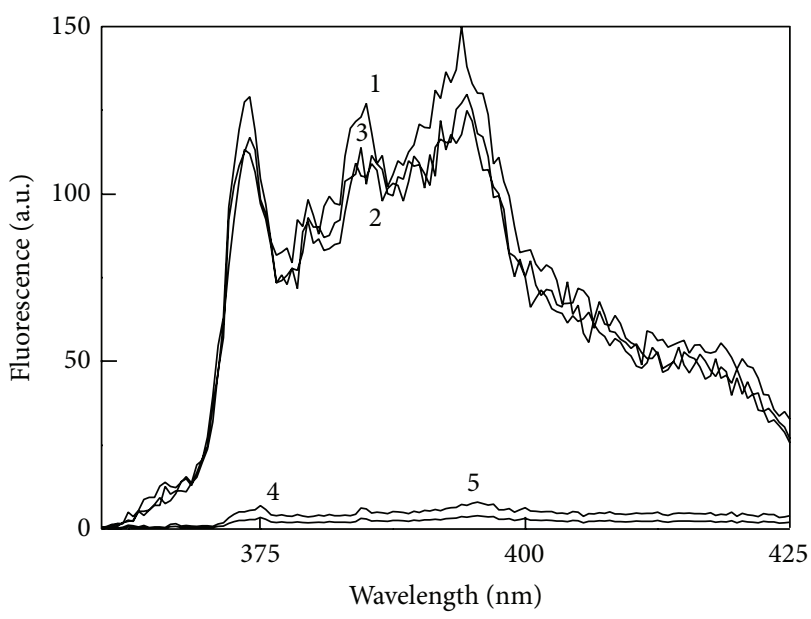

(a)

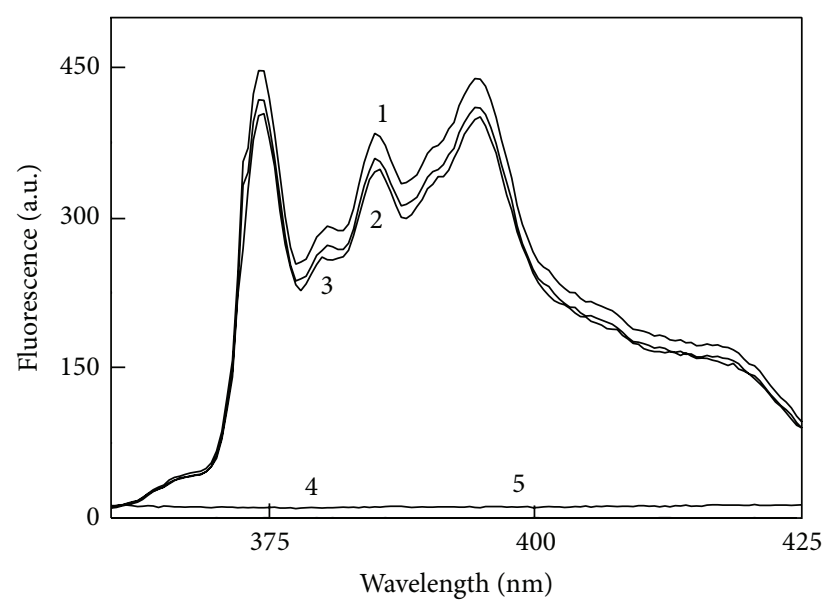

(b)

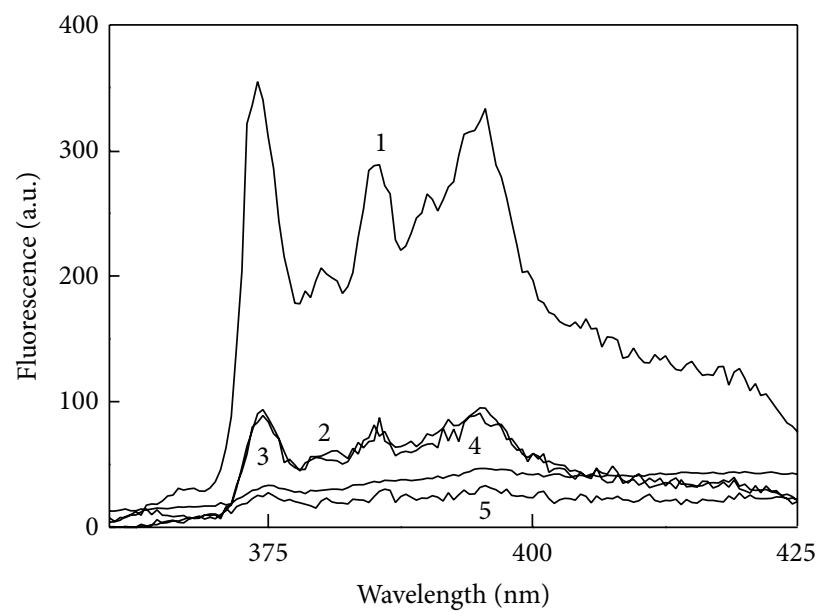

(c)

FIgURE 6: Fluorescence spectra of pyrene $\left(\lambda_{\text {exc }}=320 \mathrm{~nm}\right)$ in aqueous micellar solutions of (a) SDS, (b) CTAB, and (c) TX-100: (1) prior to sorption; after sorption on the CTS fiber, (2) polybasic and (3) polycationic forms; and on the CTS fiber, (4) polybasic and (5) polycationic forms.

Transition of PAH molecules from the aqueous macrophase to the micellar micropseudophase is known to occur in surfactant micellar media; for example, the transfer efficiency of pyrene into SDS micelles reaches 99\% [33]. Micelles can be adsorbed on the matrix and concentrate pyrene on the sorbent surface. Consequently, an increased SSF signal indicates effective interaction of the micelles with the fiber surface. These results tell us that the CTS-based fiber, probably due to its mesh structure, is well permeable to ionic surfactants and pyrene. The highly ordered fibrous CDA material, on the contrary, retains micelles with solubilized pyrene at its surface.

Of course, the nature and CMC of surfactants shall affect the extraction degree of pyrene from aqueous solution. The $\mathrm{CMC}_{1} / \mathrm{CMC}_{2}$ of the surfactants in water at $25^{\circ} \mathrm{C}$ are known to be $8.0 / 50 \mathrm{mM}$ for SDS [34], 0.9/21 mM for CTAB [35,36], and $0.2 / 1.4 \mathrm{mM}$ for TX-100 [37]; that is, the surfactant concentration used $(10 \mathrm{mM})$ was almost equal to $\mathrm{CMC}_{1}$ for SDS, 10 $\mathrm{CMC}_{1}$ for $\mathrm{CTAB}$, and $1.5 \mathrm{CMC}_{2}$ for TX-100. Apparently, this explains the differences in the pyrene fluorescence intensity in various aqueous micellar media and on our CDA fibers modified with various surfactants.

The influence of surfactants on the pyrene SSF on the CDA fibers is the subject of special studies. We have established the fact of the effective sorption of pyrene from watermicellar media on this matrix and the intense fluorescence of the probe in the sorbed state, which can be used in chemical sensors.

\section{Conclusions}

The experimental results show that the material made of CDA has a highly ordered stacking of fibers with $d=300$ $3000 \mathrm{~nm}$ and the surface potential $\xi=+419.0 \pm 1.0 \mathrm{mV}$. The material made of polycationic CTS is characterized by $\xi=$ $+116.5 \pm 1.5 \mathrm{mV}$ and a weakly ordered stacking of fibers with $d=150 \mathrm{~nm}$. The polycationic-polybasic switch in CTS leads to distortion of the fibers, their increased diameter, reduced 


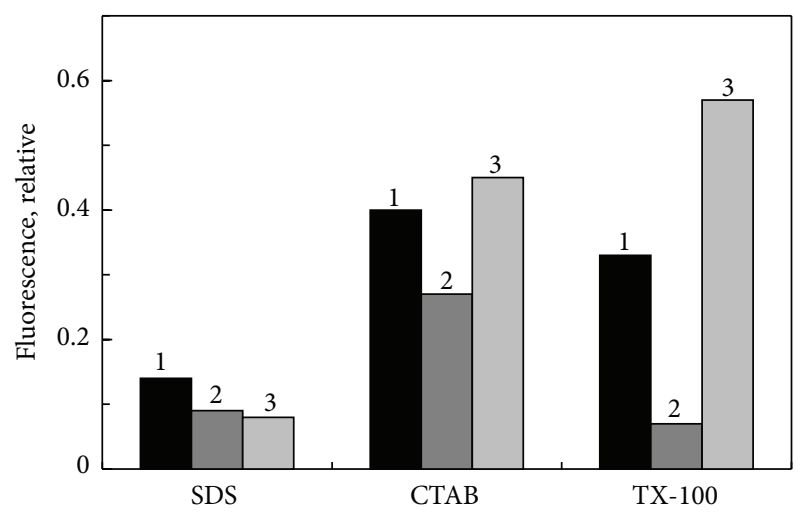

FIGURE 7: Relative pyrene fluorescence intensity in aqueous micellar media with SDS, CTAB, and TX-100: (1) prior to sorption, (2) after sorption on the CDA fiber, and (3) on the CDA fiber.

pore sizes in the material, and an inversed sign of the surface potential: $\xi=-192.5 \pm 0.5 \mathrm{mV}$.

CDA fibers are capable of sorbing trypaflavine on their surface; that is, they can be used as a matrix for SSF of this dye and similar (by chemical structure) probes. CDA fibers are also good sorbents for pyrene from water-micellar surfactant media of various types and promising matrices for its SSF.

For the CTS fibers it is shown that the SSF signal of eosin Y anions increases on the surface with the total positive charge (the polycationic form) and that of trypaflavine cations does on the surface with the total negative charge (the polybasic form); that is, the Coulomb interactions determine concentration and fluorescence of these probes on CTS matrices. The polybasic CTS fibers have the highest sorption capacity $(R=$ 95.5\%) relative to the negatively charged eosin Y.

The CTS fibers are permeable to hydrophobic pyrene dissolved in a water-ethanolic medium or solubilized in the micelles of ionic surfactants at concentrations below $\mathrm{CMC}_{2}$.

These results can be used in the design of chemical sensors.

\section{Acronyms}

CDA: Cellulose diacetate

CMC: Critical micelle concentration

CTAB: Cetyltrimethylammonium bromide

CTS: Chitosan

PAH: Polycyclic aromatic hydrocarbons

SEM: Scanning electron micrographics

SDS: Sodium dodecyl sulfate

SPE: Solid-phase extraction

SSF: $\quad$ Solid-surface fluorescence

TX-100: Polyoxyethylene (10) mono-4-isooctylphenyl ether.

\section{Conflict of Interests}

The authors declare that there is no conflict of interests regarding the publication of this paper.

\section{Acknowledgments}

The results of this work were obtained in the framework of the State Task no. 4.1299.2014/K of the Russian Ministry of Education and Science, and this study is also supported by the RFBR Grant МОЛ_a no. 12-02-31196.

\section{References}

[1] M. Safarikova and I. Safarik, "Magnetic solid-phase extraction," Journal of Magnetism and Magnetic Materials, vol. 194, no. 1, pp. 108-112, 1999.

[2] A. Poliwoda, A. M. Chrzanowska, K. Orlowska, and P. P. Wieczorek, "Membrane extraction and solid-phase extraction as effective methods for extraction and concentration of organic compounds from samples with complex matrix composition," Chemik, vol. 68, no. 4, pp. 312-320, 2014.

[3] J. L. Whitcomb and A. D. Campiglia, "Screening potential of solid-phase extraction and solid surface room temperature fluorimetry for polycyclic aromatic hydrocarbons in water samples," Talanta, vol. 55, no. 3, pp. 509-518, 2001.

[4] H. Wang and A. D. Campiglia, "Determination of polycyclic aromatic hydrocarbons in drinking water samples by solidphase nanoextraction and high-performance liquid chromatography," Analytical Chemistry, vol. 80, no. 21, pp. 8202-8209, 2008.

[5] P. P. Vazquez, A. R. Mughari, and M. M. Galera, "Solid-phase microextraction (SPME) for the determination of pyrethroids in cucumber and watermelon using liquid chromatography combined with post-column photochemically induced fluorimetry derivatization and fluorescence detection," Analytica Chimica Acta, vol. 607, no. 1, pp. 74-82, 2008.

[6] J. N. Miller, "Luminescence measurements on surfaces," Pure and Applied Chemistry, vol. 57, no. 3, pp. 515-522, 1984.

[7] R. J. Hurtubise, "Solid-matrix luminescence analysis: photophysics, physicochemical interactions and applications," Analytica Chimica Acta, vol. 351, no. 1-3, pp. 1-22, 1997.

[8] J. F. Fernández-Sánchez, A. Segura Carretero, C. Cruces-Blanco, and A. Fernández-Gutiérrez, "The development of solid-surface fluorescence characterization of polycyclic aromatic hydrocarbons for potential screening tests in environmental samples," Talanta, vol. 60, no. 2-3, pp. 287-293, 2003.

[9] G. M. Escandar, D. G. Gómez, A. E. Mansilla, A. M. De La Peña, and H. C. Goicoechea, "Determination of carbamazepine in serum and pharmaceutical preparations using immobilization on a nylon support and fluorescence detection," Analytica Chimica Acta, vol. 506, no. 2, pp. 161-170, 2004.

[10] M. Torre, M. Sánchez-Hernández, S. Vera, and M. P. San Andrés, "Improvement in retinol analysis by fluorescence and Solid Phase Extraction (SPE) in micellar medium," Journal of Fluorescence, vol. 18, no. 2, pp. 487-497, 2008.

[11] M. C. Talio, M. Alesso, M. Acosta, M. G. Acosta, M. O. Luconi, and L. P. Fernández, "Caffeine monitoring in biological fluids by solid surface fluorescence using membranes modified with nanotubes," Clinica Chimica Acta, vol. 425, pp. 42-47, 2013.

[12] I. I. Parashchenko, T. D. Smirnova, S. N. Shtykov, V. I. Kochubei, and N. N. Zhukova, "Doxycycline-sensitized solid-phase fluorescence of europium on silica in the presence of surfactants," Journal of Analytical Chemistry, vol. 68, no. 2, pp. 112-116, 2013.

[13] M. E. Germain and M. J. Knapp, "Optical explosives detection: from color changes to fluorescence turn-on," Chemical Society Reviews, vol. 38, no. 9, pp. 2543-2555, 2009. 
[14] V. G. Amelin, N. S. Aleshin, O. I. Abramenkova, Y. N. Nikolaev, and I. A. Lomonosov, "Solid-phase fluorometric determination of $\mathrm{Al}(\mathrm{III}), \mathrm{Be}(\mathrm{II})$, and $\mathrm{Ga}(\mathrm{III})$ using dynamic preconcentration on reagent cellulose matrix," Journal of Analytical Chemistry, vol. 66, no. 8, pp. 709-713, 2011.

[15] C. McDonagh, C. S. Burke, and B. D. MacCraith, "Optical chemical sensors," Chemical Reviews, vol. 108, no. 2, pp. 400422, 2008.

[16] M. Brasuel, R. Kopelman, T. J. Miller, R. Tjalkens, and M. A. Philbert, "Fluorescent nanosensors for intracellular chemical analysis: Decyl methacrylate liquid polymer matrix and ionexchange-based potassium PEBBLE sensors with real-time application to viable rat C6 glioma cells," Analytical Chemistry, vol. 73, no. 10, pp. 2221-2228, 2001.

[17] R. K. Bauer, R. Borenstein, P. de Mayo et al., "Surface photochemistry: translational motion of organic molecules adsorbed on silica gel and its consequences," Journal of the American Chemical Society, vol. 104, no. 17, pp. 4635-4644, 1982.

[18] S. Beltyukova, O. Teslyuk, A. Egorova, and E. Tselik, "Solidphase luminescence determination of ciprofloxacin and norfloxacin in biological fluids," Journal of Fluorescence, vol. 12, no. 2, pp. 269-272, 2002.

[19] S. G. Dmitrienko, E. Y. Gurariy, R. E. Nosov, and Y. A. Zolotov, "Solid-phase extraction of polycyclic aromatic hydrocarbons from aqueous samples using polyurethane foams in connection with solid-matrix spectrofluorimetry," Analytical Letters, vol. 34, no. 3, pp. 425-438, 2001.

[20] A. Moghimi and M. Alijanianzadeh, "Preconcentration of benzene and phenolic compounds in water sample by adsorption on carbon nanotubes coated fiber," African Journal of Pure and Applied Chemistry, vol. 7, no. 6, pp. 208-217, 2013.

[21] G. I. Romanovskaya, A. Y. Olenin, and S. Y. Vasil'Eva, “Concentration of polycyclic aromatic hydrocarbons by chemically modified silver nanoparticles," Russian Journal of Physical Chemistry A, vol. 85, no. 2, pp. 274-278, 2011.

[22] A. H. Ackerman and R. J. Hurtubise, "Methods for coating filter paper for solid-phase microextraction with luminescence detection and characterization of the coated filter paper by infrared spectrometry," Analytica Chimica Acta, vol. 474, no. 1-2, pp. 77-89, 2002.

[23] O. A. Dyachuk, T. I. Gubina, and G. V. Melnikov, "Adsorption preconcentration in the luminescence determination of polycyclic aromatic hydrocarbons," Journal of Analytical Chemistry, vol. 64, no. 1, pp. 7-11, 2009.

[24] P. Zugenmaier, "Characterization and physical properties of cellulose acetates," Macromolecular Symposia, vol. 208, pp. 81$166,2004$.

[25] S. Fischer, K. Thümmler, B. Volkert, K. Hettrich, I. Schmidt, and K. Fischer, "Properties and applications of cellulose acetate," Macromolecular Symposia, vol. 262, no. 1, pp. 89-96, 2008.

[26] M. Rinaudo, "Chitin and chitosan: properties and applications," Progress in Polymer Science, vol. 31, no. 7, pp. 603-632, 2006.

[27] V. K. Mourya and N. N. Inamdar, "Chitosan-modifications and applications: opportunities galore," Reactive and Functional Polymers, vol. 68, no. 6, pp. 1013-1051, 2008.

[28] M. Jabli, M. H. V. Baouab, M. S. Roudesli, and A. Bartegi, "Adsorption of acid dyes from aqueous solution on a chitosancotton composite material prepared by a new pad-dry process," Journal of Engineered Fibers and Fabrics, vol. 6, no. 3, pp. 1-12, 2011.

[29] C. Gerente, V. K. C. Lee, P. Le Cloirec, and G. McKay, "Application of chitosan for the removal of metals from wastewaters by adsorption-mechanisms and models review," Critical Reviews in Environmental Science and Technology, vol. 37, no. 1, pp. 41127, 2007.

[30] B. Valeur, Ed., Molecular Fluorescence: Principles and Applications, Wiley-VCH Verlag GmbH, 2001.

[31] R. F. Weiner and H. H. Selige, "Oxygen quenching of trypaflavine luminescence," Photochemistry and Photobiology, vol. 4, no. 6, pp. 1207-1216, 1965.

[32] K. Kalyanasundaram and J. K. Thomas, "Environmental effects on vibronic band intensities in pyrene monomer fluorescence and their application in studies of micellar systems," Journal of the American Chemical Society, vol. 99, no. 7, pp. 2039-2044, 1977.

[33] I. Y. Goryacheva, S. N. Shtykov, A. S. Loginov, and I. V. Panteleeva, "Preconcentration and fluorimetric determination of polycyclic aromatic hydrocarbons based on the acid-induced cloud-point extraction with sodium dodecylsulfate," Analytical and Bioanalytical Chemistry, vol. 382, no. 6, pp. 1413-1418, 2005.

[34] A. P. Romani, A. E. da Hora MacHado, N. Hioka et al., "Spectrofluorimetric determination of second critical micellar concentration of SDS and SDS/Brij 30 systems," Journal of Fluorescence, vol. 19, no. 2, pp. 327-332, 2009.

[35] R. Guo, X. J. Zhu, and X. Guo, "The effect of $\beta$-cyclodextrin on the properties of cetyltrimethylammonium bromide micelles," Colloid \& Polymer Science, vol. 281, no. 9, pp. 876-881, 2003.

[36] T. Liu and J. Wu, "Effect of CTAB and procain hydrochloride on neutral red microstructure in CTAB micelle," Colloid Journal, vol. 70, no. 3, pp. 311-316, 2008.

[37] D. Yu, F. Huang, and H. Xu, "Determination of critical concentrations by synchronous fluorescence spectrometry," Analytical Methods, vol. 4, no. 1, pp. 47-49, 2012. 

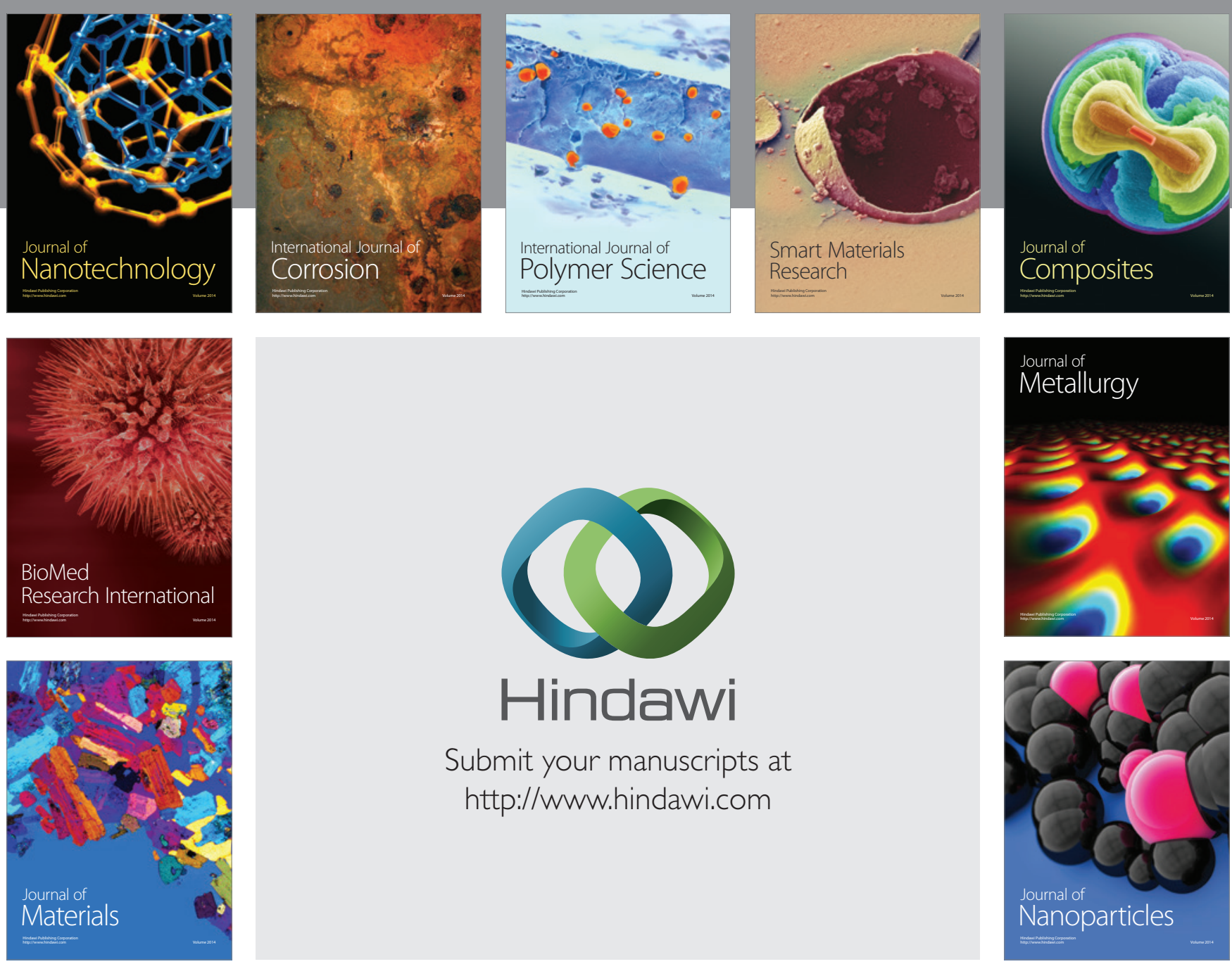

Submit your manuscripts at http://www.hindawi.com
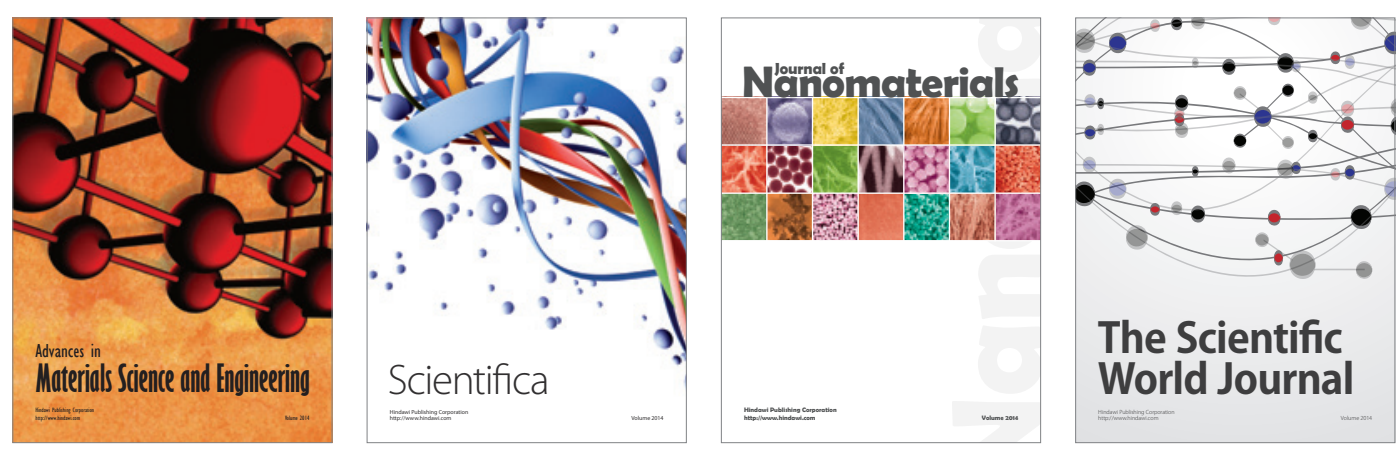

\section{The Scientific World Journal}
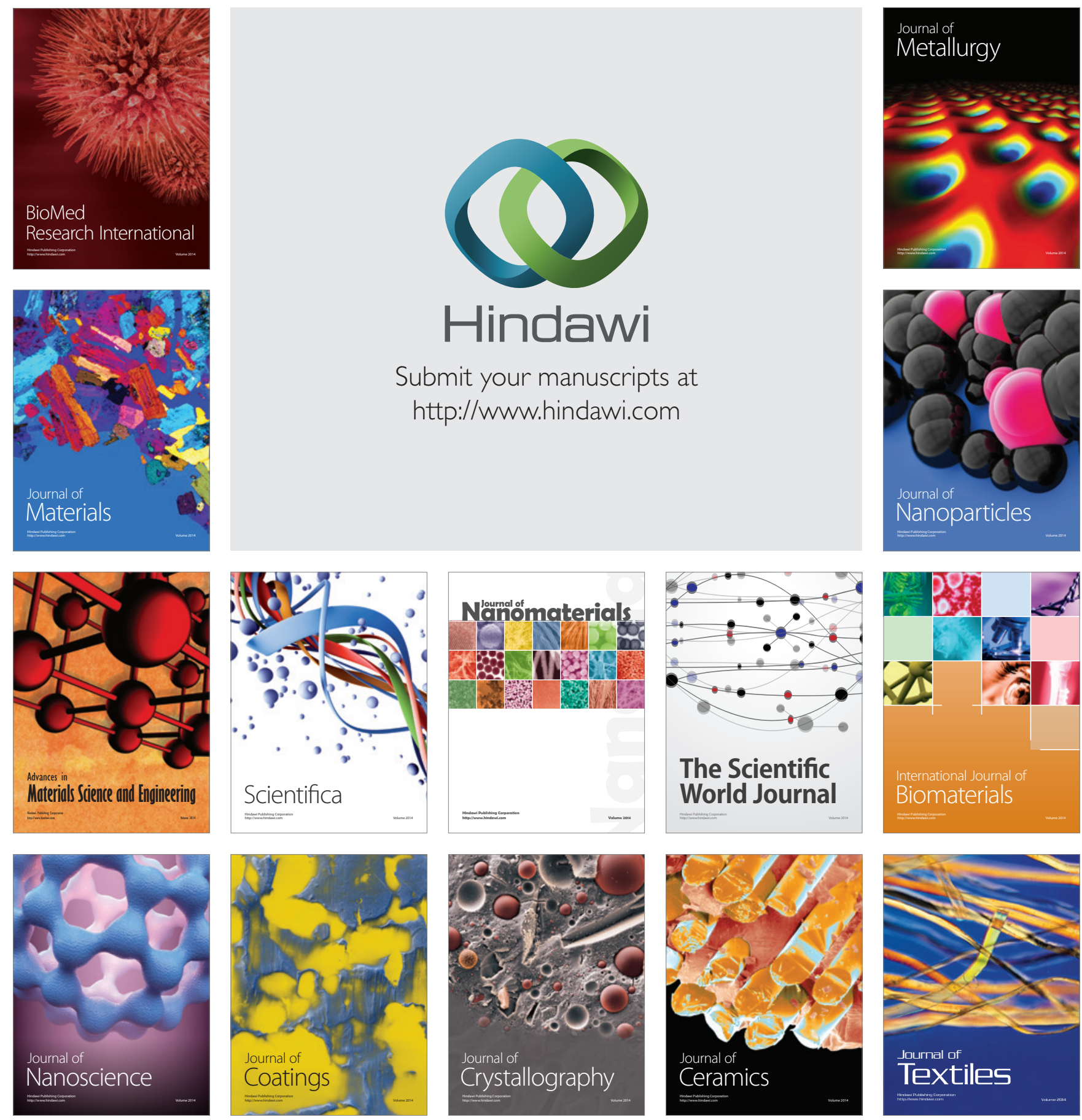